\title{
MANAJEMEN PENDIDIKAN KARAKTER DI UNIVERSITAS PANCASAKTI (UPS) TEGAL
}

\author{
Basukiyatno, Budiyono, dan Beni Habibi \\ Universitas Pancasakti Tegal \\ basukiyatnofkip@gmail.com
}

\begin{abstract}
This study attempts to mendiskripsikan management character education at the university of pancasakti tegal. This research adopting descriptive-qualitative namely research that only describes the phenomena of subject research in they are, by exposure to the results of the study qualitatively. Informants as a source of data were chosen purposively, that is set in the a person who is regarded know a lot about problems the treatment. This informant covering officials, lecturers teaching MPK, and students in a limited number of. The result of research give a description, that in oops tegal character education carried out by of several units of institutions, among others. (1) management unit matakuliah develop the character of (MPK), (2) units for student activities, (3) a unit spirituality. Concluded that third implementation unit character education has yet to walk by satisfactory. The findings from the field indicated distortion, deficiency, obstacles and overlapping management in character education. MPK can't run optimal, both in terms of management, lecturers, management learning, and evaluation. Activities kemahasiswaan had a role good for participants, honey do not all students come in it, unit spirituality is not widely known and interested in. The implications of the result of this research is character education in oops will participate and function optimally, when university pancasakti tegal could compatibly combine three implementation unit character education so the all parties concerned can optimize the role of each others.
\end{abstract}

Keywords: management, character education, student activities.

\section{Pendahuluan}

Negara berkewajiban mencerdas-

kan kehidupan bangsa. Kecerdasan manusia bersifat multidimensional. Perspektif ke dalam, manusia cerdas adalah manusia yang mampu mengenali dirinya dan potensinya sebagai dasar pembentuk Karakter Personal. Perspektif keluar, manusia cerdas adalah manusia yang mampu mengendalikan dan mengembangkan kebudayaan sebagai sistem nilai, sistem pengetahuan, dan sistem perilaku bersama melalui olah pikir, olah rasa dan olah karsa.
Selanjutnya, karakter personal dan karakter kolektif inilah yang akan menentukan perilaku manusia. Dengan kata lain, perilaku manusia adalah fungsi dari karakter personal dan karakter kolektif. Perilaku manusia Indonesia yang berisi karakter personal dan karakter kolektif ini akan terwujud hanya melalui pendidikan atau pembudayaan.

Pendidikan dari lingkungan keluarga, kerabat, komunitas dan agama yang berlangsung di ruang privat, akan menghasilkan karakter personal. Sedangkan pendidikan kebangsaan, kewarga- 
negaraan dan nilai-nilai budaya yang berlangsung di ruang publik/ pendidikan sekolah akan menghasilkan karakter kolektif. Pendidikan karakter kolektif di sekolah inilah yang kita sebut sebagai "Pendidikan Karakter". Itulah sebabnya, manakala terjadi gejala defisit manusia warga negara yang berkarakter, kita lantas menuding merosotnya pendidikan karakter di sekolah. Nilai-nilai keutamaan bangsa dirasa kian merosot akibat ketiadaannya keteladanan elit. Demikian kesimpulan wawancara Kompas terhadap sejumlah tokoh (Kompas, 11 Juli 2015)

Beberapa realitas kehidupan masyarakat yang mengarah pada tindakan negatif seperti konflik antar kelompok, korupsi, mafia kasus, tawuran siswa, miskinnya rasa toleransi, nihilnya keteladanan dan nilai keutamaan bangsa seperti musyawarah, gotong royong, adalah disebabkan oleh nihilnya pendidikan karakter di sekolah. Sebagai jawabannya, dunia pendidikan merespon positif dengan pembenahan penyelenggaraan pendidikan karakter. Sebagai contoh, Mentri Pendidikan dan Kebudayaan Anies Baswedan dalam jumpa pers tanggal 24 Juli telah mensosialisasi Peraturan Mendikbud Nomor 23 Tahun 2015 tentang Penumbuhan Budi Pekerti (Kompas, tanggal 25 Juli 2015). Dalam peraturan itu, pendidikan karakter juga ada dalam kegiatan non kurikuler, agar menjadi kebiasaan hidup siswa dan masyarakat sekolah.

Secara singkat, untuk membentuk perilaku manusia Indonesia yang berkarakter, diperlukan pendidikan atau pembudayaan sebagai wahana, adapun materi atau bahan yang akan diberikan berupa "nilai-nilai keutamaan hidup", sudah dipunyai oleh bangsa Indonesia.

Namun sejak masa Orde Baru, pendidikan karakter di Indonesia dianggap "gagal". Artinya, apa yang kita pelajari di sekolah tidak diletakkan dalam rangka memperkembangkan pribadi dan demi menghayati hidup yang baik, melainkan sekedar untuk memenuhi tuntutan-tuntutan formal akademik sekolah. Misalnya demi mendapatkan ijasah dengan Indek Prestasi yang dapat digunakan untuk memenuhi persyaratan formal guna memasuki jenjang pendidikan yang lebih tinggi, atau memasuki dunia kerja, dan menurut Adimassana (1986) dari kondisi tersebut jelas terjadi pendangkalan makna/fungsi pendidikan karakter.

Kalau dirunut lebih dalam lagi, pendangkalan pendidikan karakter ini adalah karena sistem pendidikan sekolah yang klasikal, dan semakin bercorak masal dan formal. Sehingga proses pendidikan di sekolah menjadi dangkal dan tidak mendasar. Dengan kata lain, pada level proses, pendidikan mengalami "Superfisialisasi" proses. Di permukaan, proses pendidikan dijalankan dengan serius-formal, tetapi di dalamnya kering dan minimalis.

Pada level tujuan, terjadi disorientasi pendidikan. Pendidikan yang mestinya diarahkan untuk mencapai kesempurnaan hidup sebagai manusia yang berbudaya, justru diarahkan pada tujuan yang semakin menyempit, yaitu pada pemerolehan sarana-prasarana untuk hidup secara kecukupan di bidang ekonomi semata.

Pada level sektoral, tampak sekali adanya penekanan yang semakin memusat pada sektor pendidikan formal. Sedangkan pendidikan informal banyak dilalaikan dan tidak dianggap. Akibat yang paling parah adalah bahwa pendidikan nilai/karakter menjadi hal yang dianggap tidak penting dan terpinggirkan.

Demikianlah, pendangkalan dalam pendidikan karakter ini juga merambah pada Perguruan Tinggi. Di UPS Tegal pendidikan karakter dilak- 
sanakan oleh beberapa junit, antara lain; (1) Unit Pengelola Matakuliah Pembentukan Karakter (MPK), (2) Unit-unit Kegiatan Mahasiswa, (3) Unit Kerohanian. Sebagai salah satu dosen MPK, juga pengelola unit kerohanian, merasakan bahwa ketiga unit pelaksana pendidikan karakter tersebut belum dapat berjalan dengan memuaskan. Peran MPK dirasakan rendah, terutama disebabkan pada level proses dan juga sistem pengajaran, distorsi, kekurangan, hambatan dan tumpang tindih pengelolaan.

$$
\text { Kegiatan kemahasiswaan }
$$

semarak berjalan, dan menunjukkan penampilan-penampilan yang menarik. Namun masih sering menimbulkan benturan dengan perkuliah, benturan saat ada penampilan, dan berbagai kendala lain yang perlu dicermasi.

Unit kerohanian berjalan secara rutin, juga secara insidental. Namun masih belum banyak dikenal dan diminati.di Universitas Pancasakti Tegal.

Memperhatikan paparan tersebut, permasalah penelitian ini difokuskan pada pertanyaan penelitian sebagai berikut; (1) bagaimana pengelolaan dan peran MPK di UPS Tegal dalam pendidikan karakter, (2) bagaimana pengelolaan dan peran unit kegiatan mahasiswa di UPS dalam pendidikan karakter, (3) bagaimana pengelolaan dan peran unit kerohanian UPS dalam pendidikan karakter.

\section{Metode penelitian}

Penelitian ini merupakan penerapan dari penelitian deskriptif, yang bertujuan untuk membuat deskripsi, yaitu gambaran secara sistematis, faktual dan akurat mengenai fenomena yang diselidiki. Fenomena yang diselidiki dalam penelitian ini managemen pendidikan karakter di UPS Tegal. Hal tersebut terjabarkan pada bagaimana peran kelompok mata kuliah MPK, peran unit kegiatan mahasiswa dan unit kerokhanian di UPS Tegal.

Peneliti melakukan observasi langsung, tujuannya agar peneliti dapat melihat dan merasakan, menerima informasi secara langsung sesuai dengan permasalahan dan tujuan penelitian. Dengan demikian, secara ringkas penelitian ini menggunakan metode deskriptif dengan pendekatan Self-Report.

\section{Populasi, Sampel Penelitian dan Pengumpulan Data}

Populasi dalam penelitian ini adalah semua dosen pengajar mata kuliah MPK, pejabat yang terkait dengan MPK dan sejumlah mahasiswa. Sehingga sampling yang diambil lebih selektif, "Purpusive Sampling" di mana peneliti dimungkinkan untuk memilih informan yang dianggap mengetahui informasi secara mendalam dan dapat dipercaya sebagai sumber data. Teknik pengumpulan data dengan Observasi dan Wawancara.

Observasi partisipan sehingga observer/peneliti diposisikan sebagai pengamat dan sekaligus menjadi bagian yang diamati. Peneliti dimungkinkan untuk menggali data dalam perspektif subyek yang diteliti. Dengan begitu struktur kognitif subyek yang diteliti seperti pikiran, perasaan, emosi, penilaian dan suasana hatinya dapat ditangkap lebih dalam dan lebih utuh. Peneliti berkomunikasi secara akrab dan leluasa sehingga data dapat digali optimal dan benar, sesuai dengan keadaan subyek yang di observasi.

Maksud mengadakan wawancara adalah untuk menggali struktur kognitif dan dunia makna dari perilaku subyek yang diteliti. Wawancara difokuskan pada pertanyaan yang berkaitan dengan pendapat, penilaian dan pengalaman 
subyek penelitian sebagai dosen pengajar mata kuliah MPK, dan para pejabat terkait, serta mahasiswa aktifis di kegiatan mahasiswa dan unit kerokhanian. Jawaban terhadap pertanyaan ini memberikan gambaran mengenai apa yang dipikirkan tentang substansi materi perkuliahan mata kuliah MPK, dan penilaian mereka terhadap pelaksanaan pendidikan karakter di Universitas Pancasakti Tegal. Pertanyaan mendalam juga dilakukan untuk menggali lebih dalam lagi suatu hal yang masih dipersoalkan (menjadi ganjalan). Interviewe diminta untuk memunculkan kesadaran kritis atau lebih kritis lagi dalam menanggapi sesuatu, menilai dan berpendapat tentang sesuatu.

\section{Analisis Data}

Analisis data dilakukan selama saat pengumpulan data berupa observasi dan wawancara, secara berkelanjutan dan dikembangkan sepanjang program. Bahkan analisis data dapat dilaksanakan mulai penetapan masalah, pengumpulan data, dan setelah data terkumpul. Dengan menetapkan masalah penelitian, peneliti sudah melakukan analisis terhadap permasalahan tersebut dalam berbagai perspektif teori dan metode yang digunakan.

Analisis data pada saat pengumpulan data dilakukan dengan menggunakan metode Triangulasi, yaitu dengan menggunakan multi sumber bukti. Analsis data juga dilakukan pada saat penyajian data yang dimaksud penyajian data dalam penelitian ini adalah menyajikan sekumpulan informasi yang tersusun sedemikian, sehingga memberi kemungkinan adanya penarikan kesimpulan. Penyajian yang digunakan adalah bentuk "Teks Naratif" (bentuk uraian). Agar teks naratif tidak berteletele, maka dilakukan penyederhanaan informasi yang kompleks ke dalam kesatuan bentuk yang sederhana dan selektif, atau dalam konfigurasi yang mudah dipahami.

\section{Hasil dan kesimpulan}

Berdasarkan penelitian diperoleh hasil dan kesimpulan sebagai berikut;

1. Pendidikan karakter di Universitas Pancasakti Tegal ternyata ada kaitannya dengan sejarah lahirnya dan misi yang diembannya sebagai lembaga pendidikan tinggi yang dilahirkan Golkar dan tekad untuk menjadi Benteng Pancasila dengan dibingkai harapan agar setiap lulusan yang dihasilkan dapat mengamalkan nilai-nilai luhur Pancasila.

2. Manajemen Pendidikan karakter yang dilaksanakan di tahun awal berdirinya Univeristas Pancasakti Tegal merupakan tata kelola pendidikan karakter yang dianggap ideal, justru karena suasana yang serba terbatas pada lembaga ini, yang melahirkan berbagai kesederhanaan pada semua bidang.

3. Manajemen pendidikan karakter antara lain dilaksanakan melalui Mata Kuliah Pembentukan Karakter (MPK) yang didasarkan pada Keputusan Dirjen Dikti, namun dengan misi sama dengan tahuntahun sebelumnya, yaitu lulusan yang memiliki kepribadian mantap, berpikir kritis, bersikap rasional dan demokratis, serta mengamalkan nilai-nilai Pancasila dalam kehidupan sehari-hari.

4. Pendidikan karakter UPS Tegal juga dilaksanakan melalui unit kegiatan mahasiswa, dan unit kerohanian.

5. Akibat dari berubahnya jenis mata kuliah MPK, yang memunculkan mata kuliah MPK baru dengan dosen pengajar baru sebagai dosen muda. Pada titik inilah ditemui fakta 
tentang pengakuan mereka terhadap berbagai kekurangan sebagai pengajar mata kuliah MPK.

6. Diperlukan seorang pejabat struktural pengelola MPK, sebagai lembaga di bawah Rektor yang mempunyai tugas dan tanggung jawab melaksanakan pendidikan karakter di Universitas Pancasakti Tegal.

7. Lembaga/unit MPK bertugas: (a) Sebagai perencana program, (b) Sebagai otoritas pengambil keputusan, (c) Sebagai pelaksana program, dan (d) Sebagai penanggung jawab program secara keseluruhan. Namun dalam penelitian ini diperoleh fakta bahwa peranan ini belum berjalan secara optimal. Indikator yang mendukung dari pernyataan ini adalah Progdi dan Fakultas secara dominan telah mengambil alih dalam perencanaan maupun pengambilan keputusan, sampai pelaksanaan teknis di lapangan.

8. Terdapat beberapa kekurangan dalam proses pembelajaran mata kuliah MPK, antara lain : (a) Persepsi dan asumsi dosen pengajar yang kurang tepat terhadap mata kuliah MPK, (b) sebagian dosen pengajar masih menggunakan metode konvensional dalam pembelajaran, (c) terdapat kegamangan dalam sistem evaluasi.

9. Unit kegiatan mahasiswa menunjukkan telah mendapatkan perhatian mahasiswa, namun mendanaan masih mengalami ketimpangan.

10. Unit kerohanian belum mendapatkan perhatian yang signifikan baik oleh dosen, karyawan maupun mahasiswa.

\section{DAFTAR PUSTAKA}

Imam Suprayogo dan Tabroni, 2003. Metodologi Penelitian Sosial-Agama. Bandung : PT. Remaja Rosdakarya

Dick Hartoko, (Ed). 1985. Memanusiakan Manusia Muda: Tinjauan Pendidikan Humaniora. Yogyakarta : Kanisius

Doni Koesoema. A, 2007. Pendidikan Karakter: Strategi Mendidik Anak di Zaman Global. Jakarta : Gramedia Widiasarana Indonesia

Mochtar Buchori, "Pendidikan Gagal Tanpa Partisipasi Orang Tua” BASIS JuliAgustus 2006 Hal. 13-20

J.R. Sutarjo Adisusilo, 2000. Pendidikan Nilai Dalam Ilmu-Ilmu Sosial-Humaniora. Editor: A. Atmadi dan Y. Setyaningsih, Yogyakarta: Universitas Sanata Dharma

Sukardi, 2003. Metodologi Penelitian Pendidikan : Kompetensi dan Praktiknya, Jakarta: PT. Bumi Aksara

Umar Tirtarahardja dan S.L La-Sulo, 2005. Pengantar Pendidikan (Edisi Revisi). Jakarta: PT. Rineka Cipta. 
Rusadi Kantaprawira, 2009. Filsafat \& Penelitian Ilmu-Ilmu Sosial, Bandung: AIPI Bandung

H.A.R. Tillar, 2001. Membenahi Pendidikan Nasional, Jakarta: Rineka Cipta

Topatimasang, Roem, 2007. Sekolah itu Candu, Yogyakarta: INSIST-Press

Esther Kuntjara, 2006. Penelitian Kebudayaan: Sebuah Panduan Praktis, Yogyakarta : Graha Ilmu

J.I.G.M. Drost, S.J., 1998. Sekolah: Mengajar atau Mendidik. Editor: P.J. Suwarno, dkk. Yogyakarta : Kanisius 